\title{
Research on Impact of Cooling Fan's Geometry on Nozzle's Heat Load of the Air-Cooled Diesel Engine
}

\author{
Jun Fu*,Yuan Tang, Wenhua Yuan, Guangming Li,Wei Chen and Yi Ma \\ Department of Mechanical and Energy Engineering, Shaoyang University, Shaoyang 422004, China
}

\begin{abstract}
In order to study the nozzle's temperature distribution and to reduce its heat load, the heat transfer boundary condition of nozzle has been simplified appropriately, considering the details of the convectional heat transfer inside the nozzle and the needle body contact heat transfer. Results of the simulation with ANSYS software show that the nozzle's temperature distribution is complicated and high-temperature region are concentrated in the nozzle's head. Considering the fact that the cooling fan plays an important role in reducing the heat load of air-cooled engine, the test points were reasonably selected to measure the needle valve body's temperature as well as to seek reasonable cooling fan blade numbers and the blade installation angle for the air outlet in order to improve the thermal load of the nozzle. It was found that the nozzle's temperature decreases at first but then increased when the fan blade numbers and the blade installation angle for air outlet increased, and the impact of the number of blades on the nozzle's temperature was more significant than the blade installation angle for the air outlet. With the scheme of the blade installation angle of $132^{\circ}$ with respect to the air outlet and with 20 blades, the temperature of the nozzle needle valve's head and middle decreases to $21 \mathrm{~K}$ and $7 \mathrm{~K}$ on average compared with the original scheme, which has a good effect on reducing the temperature of the nozzle's needle valve head, and the temperature gradient between two test points also reduced by $0.65 \mathrm{~K} / \mathrm{mm}$ on average. It provides a reference for reducing the nozzle's heat load.
\end{abstract}

Keywords: Cooling fan, diesel engine, fuel spray nozzle, heat load, needle valve body, temperature gradient.

\section{INTRODUCTION}

Nozzle is an important part of diesel engine's fuel supply system, its performance directly effects diesel engine's power, fuel economy and reliability of performance. At present, with the development of diesel engines that are meant to have a long life, high reliability and enhancement, its working process cycle temperature is generally higher, as a result the heat loads become greater as well [1]. Due to the particular location of nozzle, its cooling performance is limited, especially in the needle valve body's head that is directly exposed to environment with the high temperature and pressure gas. Under the action of cyclic heat load and high temperatures, carbon deposits and cavitations in the nozzle can be generated at an accelerating rate, which has harmful effects on the nozzle's normal work and reduces the hardness of needle valve couple and the life of the nozzle, this even causes deformation of the moving parts and they can get stuck $[2,3]$. Because of its own limited cooling ability, nozzle is easily damaged by large heat loads under the influence of fuel quality and other uncertainty factors, thus the nozzle loses its ability to work properly [4]. the aircooled diesel engine's heating parts use air-cooled ways and parts such as cylinder head and nozzle do not dissipate heat well, this often occurs under higher heat load because of the small air specific heat capacity and the influence of operating conditions and load changes.
Taking the 175 series small air-cooled diesel engine as an example, as a nozzle jam occurs easily under high speed and heavy load state in practical applications in it. It is essential to research the nozzle's temperature distribution and its measures to reduce the heat load. In order to solve this problem, the nozzle structure and working process are simplified appropriately, the needle valve couple's structure details and the heat transfer process's secondary factors are ignored, the heat transfer boundary conditions are determined, and the thermal simulation with ANSYS software will be carried out to get nozzle needle valve body's temperature distribution in the injection process and find out the improvement measures. After simulation, the reasonable measuring points on the nozzle are arranged. The copper-constantan thermocouple will be used to measure the temperature, it has good characteristics of stability, high precision $(0.4 \mathrm{~K})$, ability to adapt to complex temperature environments and suitable economical temperature measuring scope [5].

\section{MODELING AND SIMULATION ANALYSIS}

\subsection{Modeling}

The main parameters of 175 series air-cooled diesel engine nozzle are shown in Table $\mathbf{1}$.

Needle valve couple which consists of a needle valve and a needle valve body has an important impact on the performance of diesel engines. It is easy to cause thermal fatigue to the needle because its head directly contacts with the hot gases in the cylinder where the temperature is 
relatively higher, thus it is necessary to study its temperature distribution. The diesel engine's nozzle temperature distribution is mainly focused on the needle valve couple. Due to the selected diesel engine's single nozzle needle valve body is symmetric, so only a quarter of the model is simulated for convenient calculations. The nozzle structure and its needle valve body quarter model is shown in Fig. (1).

Table 1. Main parameters of the diesel engine's nozzle.

\begin{tabular}{|c|c|c|c|}
\hline $\begin{array}{c}\text { Plunger } \\
\text { Diameter/mm }\end{array}$ & $\begin{array}{c}\text { Geometric } \\
\text { Circulation } \\
\text { Area/mm }\end{array}$ & $\begin{array}{c}\text { Needle } \\
\text { Valve } \\
\text { Lift } / \mathbf{m m}\end{array}$ & $\begin{array}{c}\text { Pressure } \\
\text { Chamber } \\
\text { Volume } / \mathbf{m m}^{3}\end{array}$ \\
\hline \hline 6 & $0.12-0.14$ & 0.4 & 2.3 \\
\hline
\end{tabular}

(a) Structure of diesel engine's nozzle

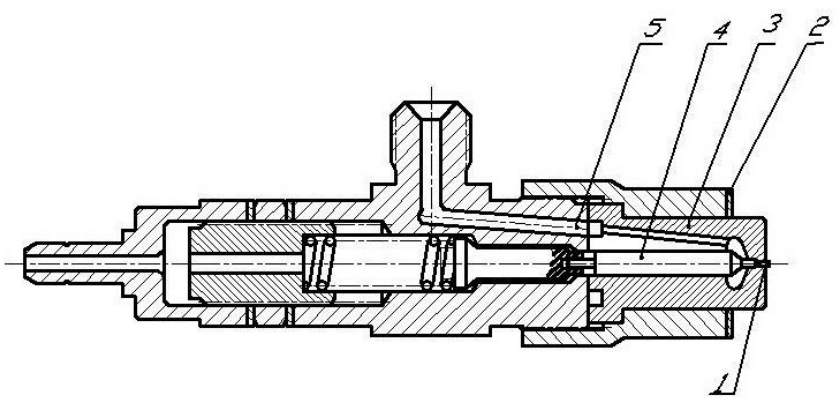

(b) Structure model of nozzle needle valve body

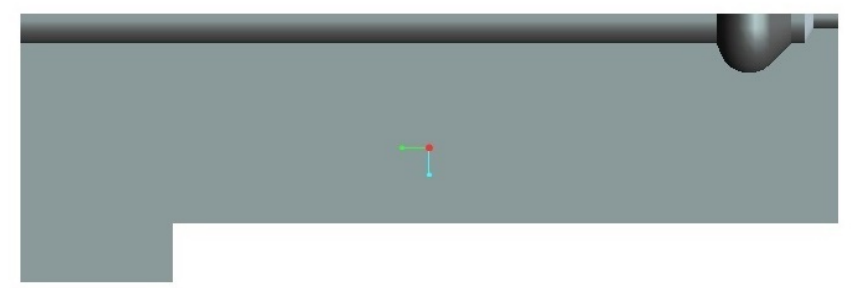

1. Nozzle hole 2 . Needle valve body 3 . Lock nut 4 . Needle valve 5. Fuel channel

Fig. (1). Nozzle's structure diagram and the needle valve's threedimensional model.

\subsection{Simplification of Heat Transfer Process}

The nozzle's actual heat transfer process is very complicated, so it must be simplified in order to perform convenient calculations: (1) Due to the engine's high rotational speed and fast heating frequency of high temperature gas on the nozzle's head, the temperature fluctuation occurs only in a very thin layer on the surface of the heated part, and the fluctuation amplitude is small which quickly decays according to the exponential regularity [6], so the heat transfer process of the nozzle is viewed as steady state. (2) The fitting clearance between the nozzle lock nut and the cylinder head and needle valve body is ignored, and the heat transfer between them is viewed as pure heat conduction. The contact parts have continuous temperature distribution, and radiation heat transfer of the cylinder head can be ignored because the cylinder head's temperature is relatively lower than the gas temperature. (3) The heat transfer of the needle valve's pressure chamber can be divided in two ways according to that the nozzle sprays fuel or not: When the nozzle spray fuel and take the heat away, the main heat transfer is through the forced convection of turbulence inside the pipe, and when the injection is stopped, the heat transfers between the fuel and the needle valve through contact. (4) Nozzle's needle valve head directly contacts with the hot gas, and the heat transfer between them is heat convection which is the main heat source of the needle's body.

\subsection{Model Parameters}

In order to study nozzle's temperature distribution, the nozzle's heat transfer mathematical model is set up. From the heat transfer knowledge [7], the heat transfer of nozzle's head is heat convection and under the steady heating of gas. According to the above-mentioned simplified conditions, the temperature can be determined by the formula (1):

$\alpha^{\prime}=\frac{1}{t} \int{ }_{0}^{t} \alpha d t ; T_{a v g}=\frac{\int_{0}^{t} \alpha T d t}{\int{ }_{0}^{t} \alpha d t}$

In the formula, $\alpha$ is the gas average heat transfer coefficient in a working cycle, and it is viewed as 376.43 $\mathrm{W} /(\mathrm{m} \cdot \mathrm{K})$ according to the reference [8]; $\alpha$ is the gas' instantaneous heat transfer coefficient, and it can be calculated by the experience formula and corrected by the experimental value [8]; $T_{a v g}$ is the integrated average temperature of gas in a working cycle, and its unit is K. $T$ is the gas instantaneous temperature, and it can be acquired by the diesel engine indicator diagram.

The central part of the nozzle is embedded in a lock nut, and its outer surface temperature has the same average testing value of $472.5 \mathrm{~K}$ as the cylinder's head. Nozzle's material is $\mathrm{GCr} 15$, and its coefficient of thermal conductivity is around 30 to $40 \mathrm{~W} /(\mathrm{m} \mathrm{K})$. During injection, the velocity of fuel flow in the nozzle's pressure chamber and around the needle valve is not very large, and its thermal conductivity is same as the central part of the nozzle. There is a larger fuel flow velocity inside the spray nozzle hole, and its heat transfer is viewed as forced convection of turbulence inside the pipe, and its heat transfer coefficient, which is selected as the dimensionless number in accordance with references [9, 10] and can be determined by the corrected Dittus-Boelter formula according to the similarity principle.

$$
N u_{f}=0.023 \operatorname{Re}_{f}^{0.8} \operatorname{Pr}_{f}^{n}
$$

In the formula (2), $n$ is equal to 3 in the cooling time; $N u_{f}$ is the dimensionless temperature gradient Nusselt number of fluid on the wall; $\mathrm{Re}_{f}$ is the dimensionless Reynolds number of the ratio between inertia force and viscous force, and it is equal to $\rho V L / \mu ; \rho$ is fuel density, and its value is $850 \mathrm{~kg} / \mathrm{m}^{3} ; V$ is the flow characteristics of velocity and can be acquired by the nozzle simulation of three dimensional flow field [11], and it's about $200 \mathrm{~m} / \mathrm{s}, \mathrm{L}$ is the characteristic length of flow field and nozzle hole diameter is set as $0.8 \mathrm{~mm} ; \mu$ is the fuel viscosity coefficient, and it's $0.005 \mathrm{~kg} /(\mathrm{m} \cdot \mathrm{s})$; $\operatorname{Pr}_{f}$ is the dimensionless Prandtl number of measuring momentum diffusion ability and heat diffusion capacity, and it is equal to $c_{p} \mu / k$, where $c_{p}$ is the constant pressure heat capacity which is about $1.2 \times 10^{7} \mathrm{~J} / \mathrm{kg}$, 
and $k$ is the fuel heat conduction coefficient, about $0.12 \mathrm{~W} /(\mathrm{m} \cdot \mathrm{K})$. Here, fuel temperature of the nozzle's pressure chamber can be obtained by the test, and fuel temperature inside the nozzle's hole is same as the nozzle head's. During the end of the fuel injection, the heat transfer process can be viewed as a adiabatic process because the heat loss is small in the nozzle pressure chamber and the nozzle hole.

\subsection{Analysis of Simulation Results}

The temperature distribution of the nozzle is calculated by simulation model of the needle valve body with ANSYS software which can generate a higher quality mesh with its Smart grid division method [12]. The mesh of the needle valve body is generated by a mesh type made from 3D Tet 10 node 87 units, and can meet the calculation precision and is shown in Fig. (2).

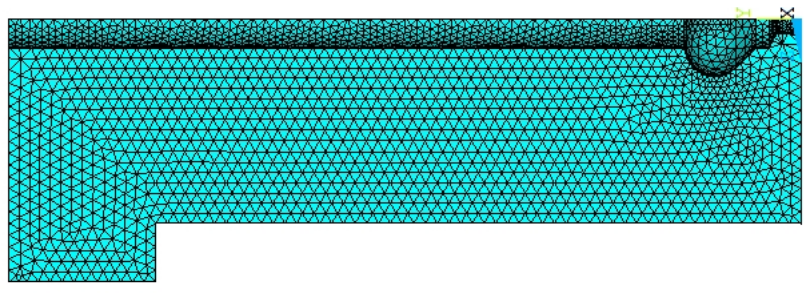

Fig. (2). Mesh of the needle valve body.

We know that nozzle failure often occurs under the conditions of high speed and large loads, so the simulation starts at the top dead center (TDC) when the crankshaft angle $\left({ }^{\circ} \mathrm{CA}\right)$ is $0{ }^{\circ} \mathrm{CA}$ under the full load and rated engine speed. The temperature field of the needle valve body is calculated through the simulation according to the obtained parameters such as gas temperature and heat transfer coefficient. The temperature field of the needle valve body, shown in Fig. (3), are in two states: one state is the moment of maximum fuel injection rate when the crankshaft angle is $-8{ }^{\circ} \mathrm{CA}$, and another is at the end of injection at the crankshaft angle 10 ${ }^{\circ} \mathrm{CA}$.

As mentioned in Fig. (3), the temperature decreases along the axial of needle valve body from head to tail, but there is small difference in the same horizontal plane along the circumferential direction. Due to the complex heat environment, the needle head is under high temperature and large thermal load, and the maximum temperature of the needle valve body's head reaches $478.9 \mathrm{~K}$ at the crankshaft angle $8{ }^{\circ} \mathrm{CA}$. When the fuel injection is paused, strong convective heat is transferred from the pressure chamber, and the nozzle hole is also terminated and the nozzle's heat environment is deteriorated, so the maximum temperature of the needle's valve body head rises to $488.5 \mathrm{~K}$ at $10{ }^{\circ} \mathrm{CA}$. Under the influence of fuel heat transfer inside the needle valve's pressure chamber and its complex geometry structure, the temperature distribution on the needle valve body's head and around the nozzle hole are highly irregular, and the highest temperature is close to the material's tempering temperature, which can lead to the fault of "sticking" needle valve. Therefore effective measures should be taken to improve the cooling performance and to reduce the heat load. And the temperature distribution in the middle part of the needle valve, which is relatively uniform, and which will not have a significant impact on it.

(a) Needle body's temperature field of Crank Angle $-8{ }^{\circ} \mathrm{CA}$
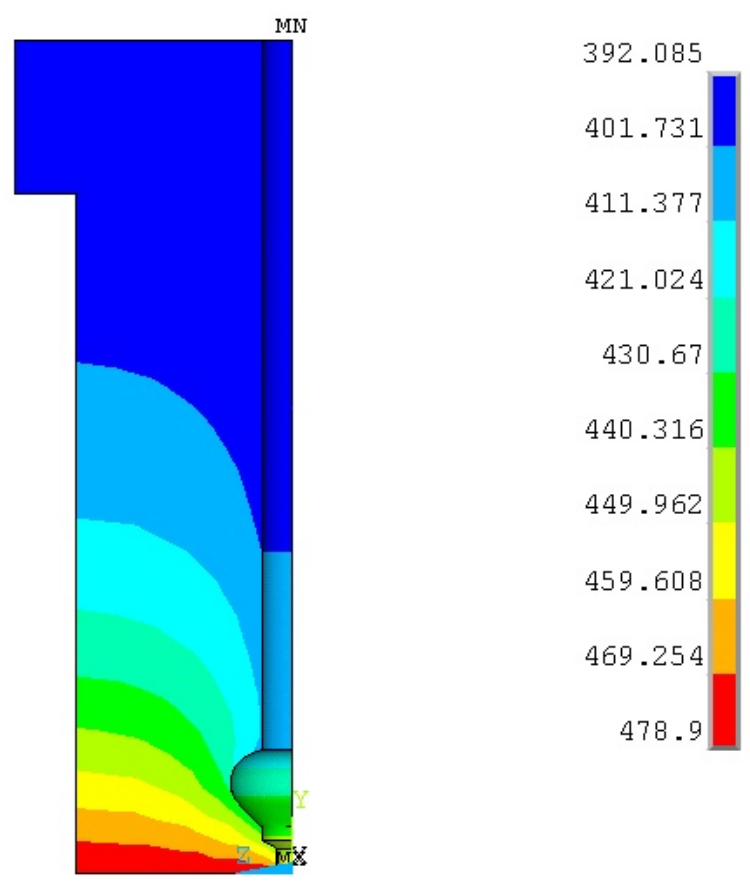

(b) Needle body's temperature field of Crank Angle $10^{\circ} \mathrm{CA}$

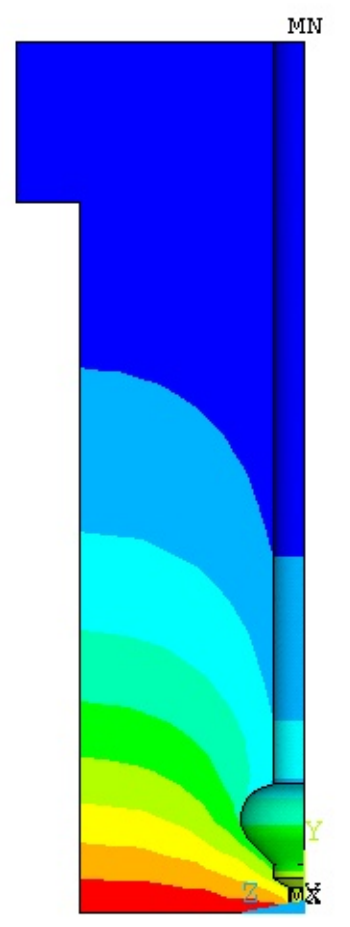

398.106
408.15
418.193
428.237
438.281
448.325
458.369
468.412
478.456
488.5

Fig. (3). Temperature field of needle valve body in different working time.

\section{EXPERIMENTAL CONDITIONS AND DESIGN}

\subsection{Experimental Conditions}

According to the simulation results of temperature distribution and considering the fact that the cooling fan has 
an important influence on the heat load of the air-cooled diesel engine without changing the engine structure and working parameters. The method of selecting the appropriate blade installation angle of air outlet and blade numbers for the cooling fan are taken into perspective, in order to improve the heat load of the nozzle. In addition, the effects of blade installation angle and blade number on the nozzle's heat load can be investigated according to the original machine parameters, design experiences and the design principle of experiment [13]. The engine's automatic control system of FC2000 type is produced by the XIANGYI motive power test instrument Co., Ltd. and it is used to monitor and store real-time parameters such as diesel engine power, rotational speed, torque, fuel temperature and fuel consumption. The engine test bench is shown in Fig. (4).

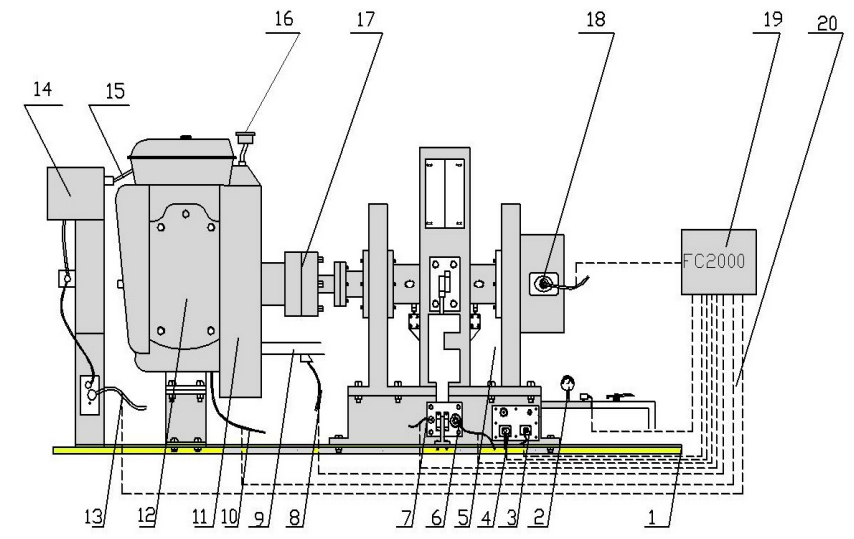

1. Test bench bed 2. Hydraulic pressure gauge 3. Control signal input lines 4. Torque signal lines 5. Hydraulic dynamometer 6. Temperature sensor 7. Water level sensor 8. Exhaust temperature sensor signal lines 9. Exhaust pipe 10. Oil temperature signal lines 11. Cooling fan dome 12. Engine 13. Fuel flow signal lines 14. Fuel consumption instrument 15. Pipeline 16. Air filter 17. Coupling 18. Speed sensor 19. FC2000 Control box 20. Connecting wire

Fig. (4). Engine test bench.

\subsection{Arrangement of Temperature Test Points}

According to the simulation results in Fig. (3). As the nozzle head is in complex temperature environment, under working conditions of higher temperature and complex temperature distribution, careful attention must be paid to it. The first test point group is set up at a location which is 0.8 $\mathrm{mm}$ away from nozzle's head in order to find out its temperature distribution under the condition of welding thermocouples reliably and trying not to affect performance of the needle valve. Due to the middle and the tail of the nozzle, which yields better cooling performance and larger temperature gradient are connected to the lock nut and they are installed on the cylinder head, the second test point group is set up at the location that is $20 \mathrm{~mm}$ away from the nozzle's head in order to research the whole temperature distribution of the nozzle. There are 6 test points in the two groups and each group has 3 test points that are set up with an interval of $120^{\circ}$ between each other along the outer cylinder surface of the nozzle. The arrangement diagram of the two test point groups is shown in Fig. (5).

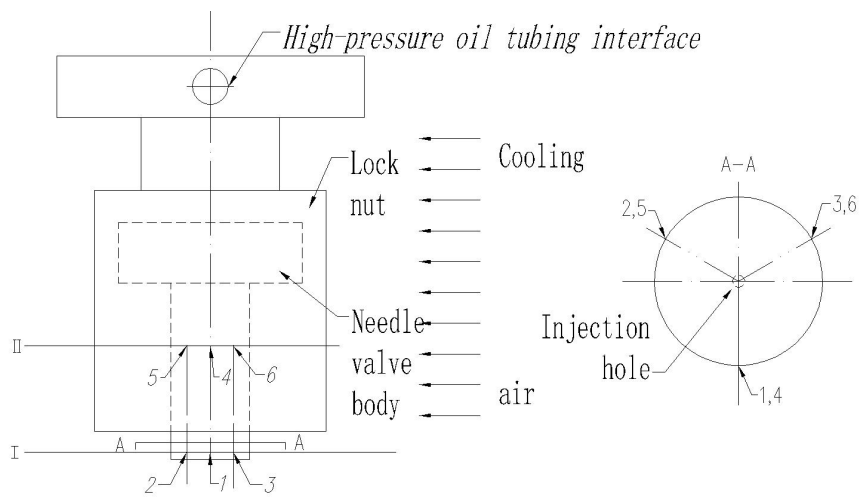

Fig. (5). Six test points arrangement diagram of the nozzle needle valve body.

\section{EXPERIMENTAL RESEARCH}

\subsection{Structure of the Cooling Fan}

Based on consideration of light weight and compactness, engineering plastic is used in the fan body. The basic parameters, such as diameter of cooling fan and its blade width and height are calculated on the basis of the required parameters such as air pressure and cooling air volume [14]. In the test study, the range of fan blade number is taken from 14 to 24 with interval of 2 , and the range of blade installation angle of air outlet from $126^{\circ}$ to $134^{\circ}$ with interval of $2^{\circ}$. Basic structure parameters of the cooling fan are shown in Table 2.

Fig. (6) shows an actual cooling fan with 20 blades and the blade installation angle of $128^{\circ}$ for the air outlet as well as the calculation diagram of the blade installation angle of air outlet. The $\beta$ is the blade installation angle for air outlet, which is the included angle between the direction of $\omega$ and the opposite direction of $v$; the $\omega$ is relative velocity of airflow and $v$ is the circumferential velocity; $\beta$ is equal to $\alpha_{1}+\alpha_{2}$, and $\alpha_{1}$ and $\alpha_{2}$ can be measured by the measuring instrument of blade angle [15].

\subsection{The Test Results and Analysis}

The test is studied under the condition of high speed and large load, where the nozzle is prone to fault. At the same time, the full load with rotation speed of $2400 \mathrm{rpm}$ is selected for the test to ensure that the experimental conditions remain unchanged and to ensure that the engine can work stably for a long period of time. In addition, for the convenience of calculation and analysis, the temperature among two test points are recorded after weeding out the bad temperature values and processing the average temperature

Table 2. Basic structure parameters of the cooling fan.

\begin{tabular}{|c|c|c|c|c|c|c|}
\hline Project & $\begin{array}{c}\text { Fan Outer Diameter } \\
(\mathbf{m m})\end{array}$ & $\begin{array}{c}\text { Fan Inner Diameter } \\
(\mathbf{m m})\end{array}$ & $\begin{array}{c}\text { Blade Height } \\
(\mathbf{m m})\end{array}$ & $\begin{array}{c}\text { Blade Width } \\
(\mathbf{m m})\end{array}$ & $\begin{array}{c}\text { Blade } \\
\text { Number }\end{array}$ & Blade Installation Angle of Air Outlet $\left.\mathbf{(}^{\circ}\right)$ \\
\hline \hline Cooling fan & 255 & 178 & 36 & 36 & $14-24$ & $126-134$ \\
\hline
\end{tabular}


values based on Bessel formula and Lauta algorithms [16, 17]. It is found that the temperature value of the test points varies from different schemes, but they show the same change regularity in these schemes. The two test point groups temperature of every scheme under the condition of $2400 \mathrm{r} / \mathrm{min}$ and full load are shown in Fig. (7).

(a) The entity of 20 blades cooling fan.

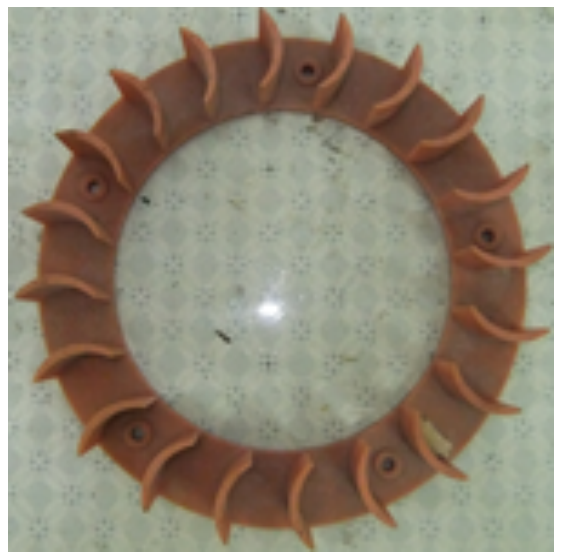

(b) Diagram of the blade installation angle of air outlet.

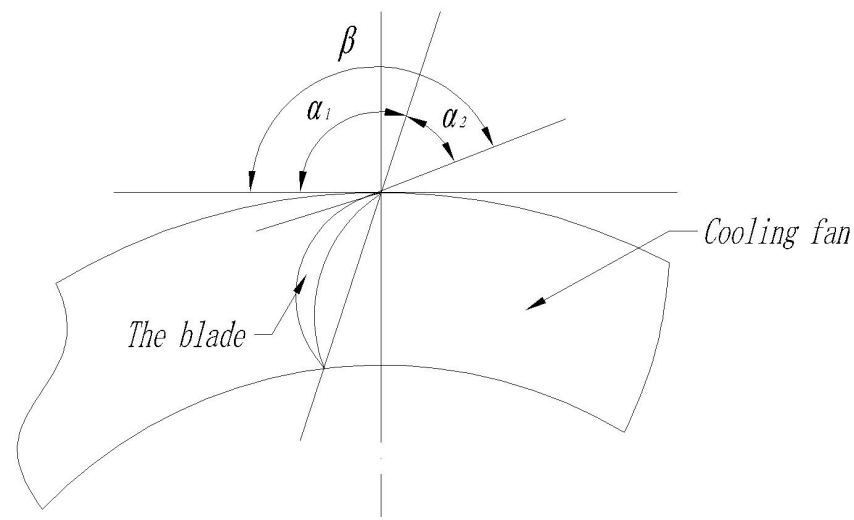

Fig. (6). Actual cooling fan and diagram of the blade installation angle of air outlet.

Ignoring the error that results from factors such as thermocouple welding, it can be seen that in Fig. (7), temperature in the middle part of the nozzle is $25 \mathrm{~K}$ lower than the nozzle head because the middle part of the nozzle is far away from complicated working environment inside the cylinder and is connected to cylinder head that is in a better cooling condition. It is found that the nozzle temperature decreases at first and then increases when the blade installation angle of air outlet increases under the condition of constant fan blade number, and the temperature reaches its lowest point when the blade installation angle of air outlet reaches the angle between $130^{\circ}$ and $132^{\circ}$. The temperature of nozzle head and middle part are $12 \mathrm{~K}$ and $15 \mathrm{~K}$ lower on average than the temperature under the condition of $126^{\circ}$ blade installation angle. It can also be seen that the nozzle temperature decreases at first and then increases when the fan blade number increases under the same blade installation angle of air outlet, and there is the lowest temperature when the fan blade number reaches 20-22. The temperature of nozzle head and middle part are $30 \mathrm{~K}$ and $15 \mathrm{~K}$ lower on average than the temperature under the condition of 14 fan blades. (a) Three test points' average temperature of the first point group

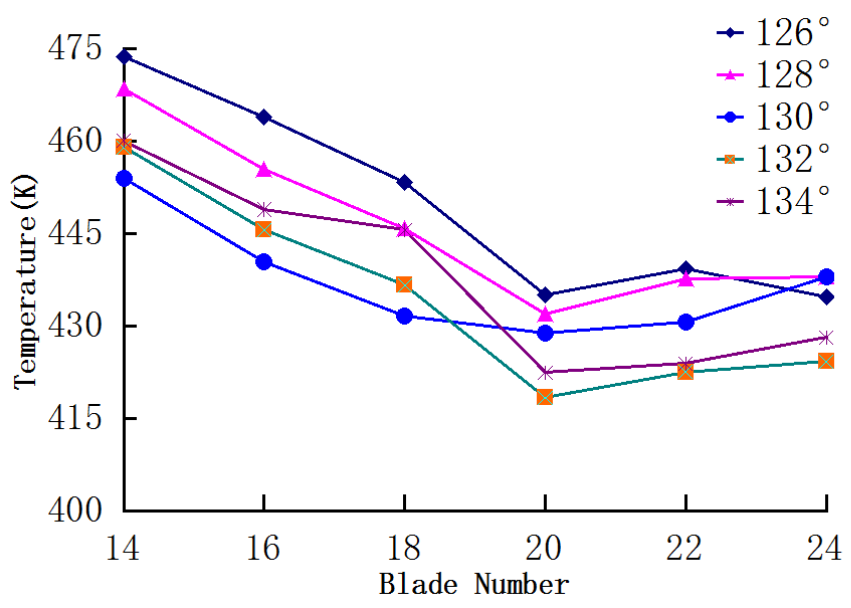

(b) Three test points' average temperature of the second point group

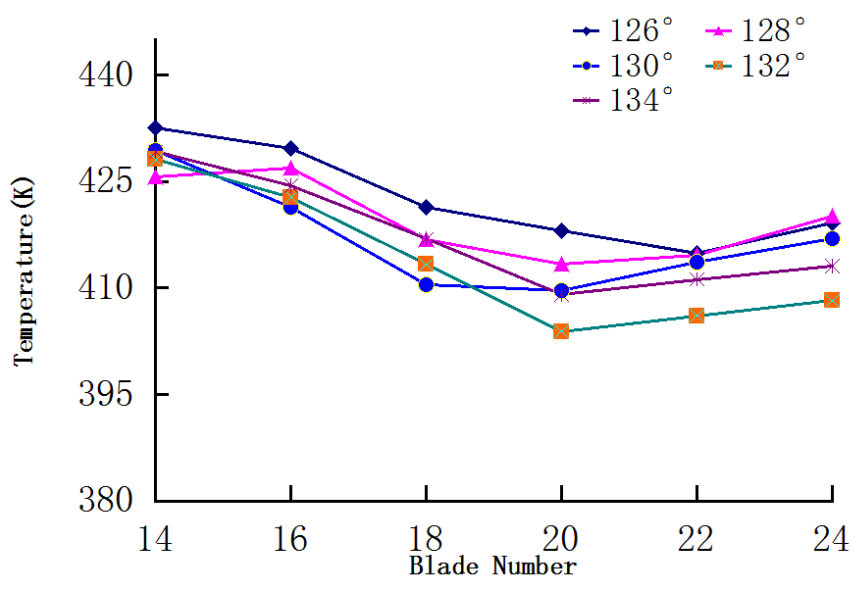

Fig. (7). The two test point groups' temperature under the condition of $2400 \mathrm{r} / \mathrm{min}$ and full load.

From the analysis of fluid mechanics [18], we know that too few number of blades or very small blade installation angle for the air outlet makes a larger channel expansion angle between the blades, thus causing lesser airflow velocity, and results in the reduction of air volume, air pressure and efficiency of the cooling fan. If the blade installation angles of air outlet are too large or if there are too many blade, this leads to a small interior circulation cross-sectional area of the channel between the blades, and rapidly increases the airflow loss along its way and airflow resistance losses of the channel between the blades. This also reduces the air volume, air pressure and efficiency of the cooling fan and finally results in deterioration of the cooling effect.

In order to study the change regularity of temperature gradient between the nozzle's head and the middle part more intuitively, when the blade installation angle of air outlet is varied, the results of original 20 blades fan and 18 blades fan are selected as the comparison objects, and the temperature distribution and its gradient distribution of the two test point groups are shown in Fig. (8). 
(a) The two test point groups' temperature change regularity of original 18 blades fan

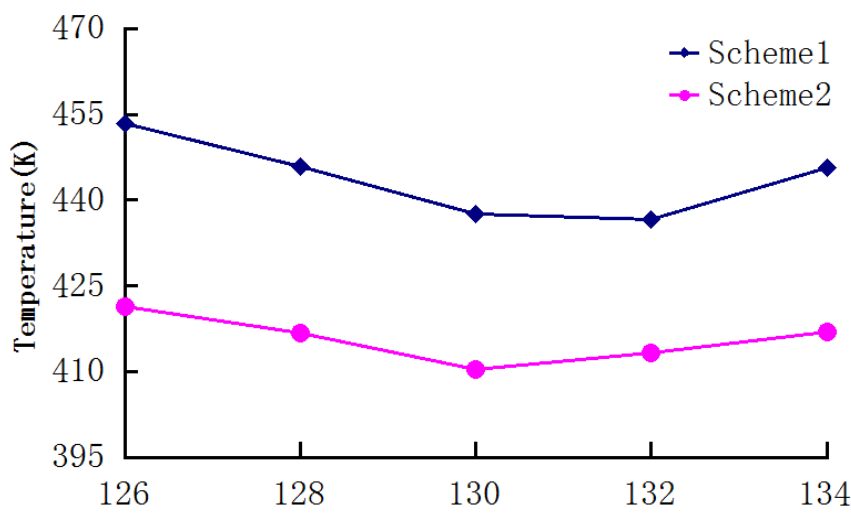

Blade Installation Angle of Air Outlet $\left(^{\circ}\right)$

(b) The two test point groups' temperature change regularity of original 20 blades fan

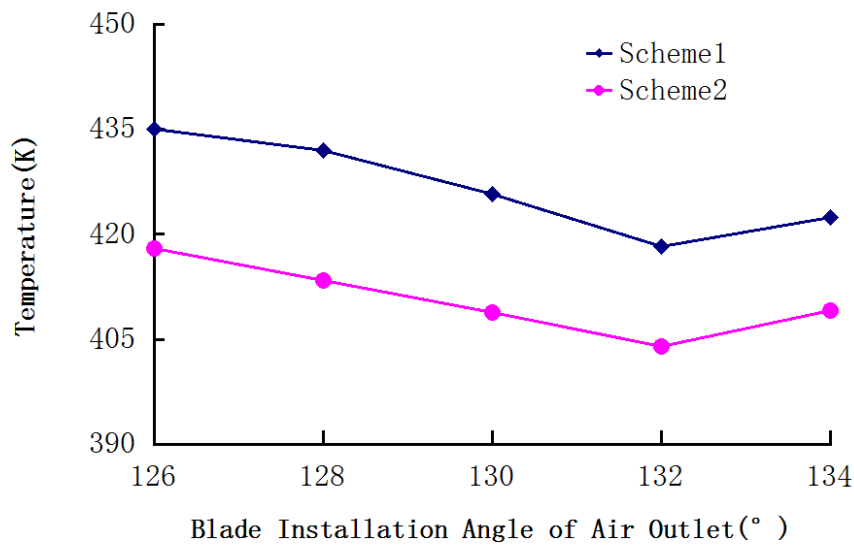

Fig. (8). The temperature distribution and its gradient distribution of the two test point groups.

As shown in Fig. (8), temperature of the nozzle's head and the nozzle's middle part reach $442 \mathrm{~K}$ and $411 \mathrm{~K}$ respectively, when the blade installation angle for the air outlet of the original fan reaches about $130^{\circ}$. The average temperature gradient of the nozzle's head and middle part reaches $1.75 \mathrm{~K} / \mathrm{mm}$ in a $20 \mathrm{~mm}$ span between the two test point groups. In the scheme of the 20 blades, the temperature and its gradient of the nozzle is minimum when the blade installation angle of air outlet reaches $132^{\circ}$, and temperature of the nozzle head and the nozzle's middle part respectively reach $421 \mathrm{~K}$ and $404 \mathrm{~K}$, where the average temperature gradient is only $1.1 \mathrm{~K} / \mathrm{mm}$. Therefore, the change of the blade installation angle for air outlet has a smaller effect on the nozzle's temperature and the temperature gradient, the temperature difference in the span of blade installation angle is kept at $15 \mathrm{~K}$ in the schemes of the same blade number. In order to study the change regularity of the nozzle's temperature and its temperature gradient when the fan blade number is changed, the results of the blade installation angle of air outlet with $130^{\circ}$ and $132^{\circ}$ are selected as the comparison objects, and the average temperature distribution and its gradient distribution of the two test point groups are shown in Fig. (9). (a) The temperature of the blade installation angle $130^{\circ}$ of air outlet

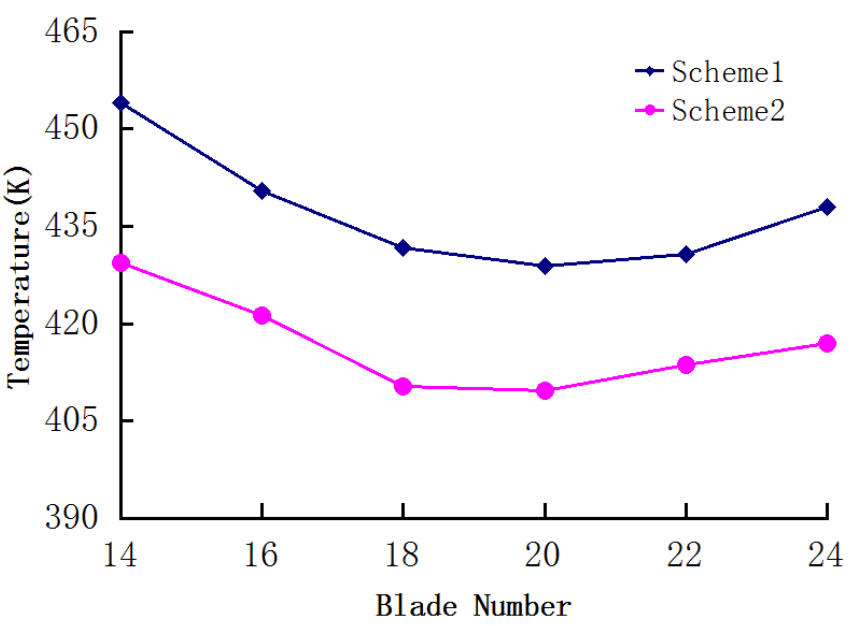

(b) The temperature of the blade installation angle $132^{\circ}$ of air outlet

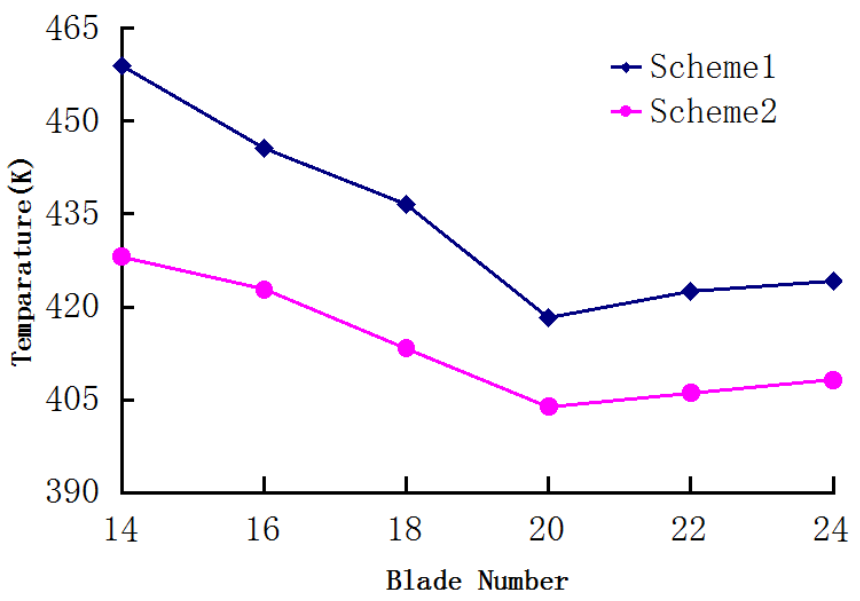

Fig. (9). The two test point groups' temperature changes with different blade numbers.

From the Fig. (9), it can be seen that the temperature and temperature gradient of each scheme is minimum when the blade number is between 20-22, and the change of the blade number has a lager effect on the temperature and temperature gradient of the nozzle. Relatively, the scheme of 14 blades is unreasonable because temperature and temperature gradient are both larger, but selecting a cooling fan with 20 blades and the blade installation angle of $132^{\circ}$ for the air outlet can not only reduce the temperature of the whole nozzle's needle valve body, but also can decrease its average axial temperature gradient to $0.65 \mathrm{~K} / \mathrm{mm}$ in a $20 \mathrm{~mm}$ span between the two test point groups.

\section{CONCLUSION}

(1) Under the same fan blade number, temperature of the nozzle's head and middle part decreases at first and then increases when the blade installation angle of air outlet increases from $126^{\circ}$ to $134^{\circ}$, and reaches a minimum temperature when the angle are positioned between $130^{\circ}$ to $132^{\circ}$. The change of the blade installation angle for air outlet has a smaller effect on the nozzle's temperature. 
(2) Under the same blade installation angle for air outlet, the nozzle's temperature decreases at first and then increases when the fan blade number increases from 14 to 24 , and reaches minimum temperature when the blade number is between 20 to22. The change in the number of blades has a lager effect on the nozzle's temperature.

(3) The scheme of cooling fan with 20 blades and $132^{\circ}$ blade installation angle for air outlet has a remarkable effect on improving the heat load of the nozzle. In this scheme, temperature of nozzle's needle valve head and middle decrease at $21 \mathrm{~K}$ and $7 \mathrm{~K}$ on average compared with the original scheme, and the temperature gradient between two test points reduce by $0.65 \mathrm{~K} / \mathrm{mm}$ on average.

\section{CONFLICT OF INTEREST}

The authors declare that there is no conflict of interest regarding the publication of this article.

\section{ACKNOWLEDGEMENTS}

This project are supported by the Innovation Platform Open Foundation in Higher Educational Institutions of Hunan Province (ID: 12K130), the Aid Program for Science and Technology Innovative Research Team in Higher Educational Institutions of Hunan Province, the Innovation Platform Open Foundation in Higher Educational Institutions of Hunan Province (ID: 09K104) and the Postgraduate Innovative Research Project of Shaoyang University.

\section{REFERENCES}

Y. Yuan, Z. Wang, and P. Sun, and D. Chen, "Research on thermal loads of small-bore air-cooling diesel engines", Journal of Agricultural Machinery, vol.36, pp.16-19, June 2005.

[2] X. Wang, and W. Su, "Numerical investigation on relationship between injection pressure fluctuations and unsteady cavitation processes inside high-pressure diesel nozzle holes", Fuel, vol.89, pp.2252-2259, January 2010.

[3] S.J. Liu, J. Wang, Z.D. Yu, D. Tang, B.F. Yin, "Fuel injection nozzle used on small bore diesel engine with swirl combustion chamber", Transactions of the CSAE, vol.19, pp.124-127, March 2003.

[4] P. Si, H. Liu, H. Wang, L.C. Kong, S.J. Li, Z.Q. Zheng, "Effects of fuel properties on low temperature combustion processes and emissions of diesel engines" Transactions of CSICE, vol.32, pp.613, January 2014.

[5] M. Genix, P. Vairac, and B. Cretin. "Local temperature surface measurement with intrinsic thermocouple", International Journal of Thermal Sciences, vol.48, pp.1679-1682, October 2009.

[6] Z. Wang, and W. Su, "Study on the decay characteristic of the thermal wave", College Physics, vol.27, pp.46-48, May 2005.

[7] T. Lestina, R. W. Serth, Process Heat Transfer: Principles and Applications, Manhattan, New York: Academic Press, Inc, 2007.

[8] J. Yuan, G. OuYang, L. Yang, and Z. Liu, "3-D finite element analysis of the thermal load of nozzle in diesel engine", Vehicle Engine, vol.1, pp.64-67, April 2006.

[9] M. Jia, M. Xie, H. Liu, W. Lam, and T. Wang, "Numerical simulation of cavitation in the conical-spray nozzle for diesel premixed charge compression ignition engines", Fuel, vol.90, pp.2652-2661, August 2011.

[10] R. Payri, J. Gimeno, P. Marti-Aldarav, and G. Bracho "study of the influence of the inlet boundary conditions in a LES simulation of internal flow in a diesel injector", Mathematical and Computer Modelling, vol.57, pp.1709-1715, March 2013.

[11] F.J. Salvador, J. Martínez-López, M. Caballer, and C. D. Alfonso, "Study of the influence of the needle lift on the internal flow and cavitation phenomenon in diesel injector nozzles by CFD using RANS methods", Energy Conversion and Management, vol.66, pp.246-256, February 2013.

[12] Li Ying, "Simulation and Application of Solid-liquid Coupled Heat Transfer in Internal Combustion Engines", Ph.D. thesis, Zhejiang University, Hangzhou, Zhe Jiang Province, China, April 1, 2006.

[13] J. Fu, J. Gong, Q. Zuo, W. H. Yuan, W. Tang, and N. Tang, "Optimum control of fuel injection and air supply for burner-type diesel particulate filter regeneration", Transactions of the Chinese Society of Agricultural Engineering (Transactions of the CSAE) vol.28, pp.11-18, September 2012 .

[14] S. Zhong, "A Research on the Methods for Designing and Calculating Performances of Engine Cooling Fans", Ph.D. thesis, South China University of Technology, Guangzhou, Guang Dong Province, China, December 1, 2011.

[15] Z. Tang, "A Research on Parameters of Engine Cooling Fan Blade and Optimization", Ph.D. thesis, South China University of Technology, Guangzhou, Guang Dong Province, China, November $1,2012$.

[16] L. Guan, J. Wang, and D. Chen, "3-D finite element analysis of microengine cylinder temperature field and heat deformation", Tsinghua University (Science and Technology), vol.43, pp.14871490, November 2003.

[17] J. Fu, W. H. Yuan, B. Wang, W. Chen, and J. K. Gong, "Establishment and application of MAP for regeneration back-pressure threshold value of diesel particulate filter", Transactions of the Chinese Society of Agricultural Engineering (Transactions of the CSAE), vol.29, pp.47-56, December 2013

[18] D. Zhang, Computational Fluid Dynamics, Beijing: Higher education press, 2010. 